http://www.jfas.info

\title{
OPTIMAL CAPACITOR SIZING AND PLACEMENT BASED ON REAL TIME ANALYSIS USING PSO FOR ENERGY EFFICIENCY IMPROVEMENT
}

\author{
A. H. A. Rahman, M. F. A. Latip* and N. Zaini \\ Faculty of Electrical Engineering, Universiti Teknologi MARA, 40450 Shah Alam, Selangor, \\ Malaysia
}

Published online: 05 October 2017

\begin{abstract}
In this paper, optimal capacitor sizing and placement method was used to improve energy efficiency. It involves the placement of capacitors in a specific location with suitable sizing based on the current load of the electrical system. The optimization is done in real time scenario where the sizing and placement of the capacitors are made dynamic and vary based on the present load of the system. PSO AI technique have been implemented for real-time analysis. The optimization technique reduce the power losses and energy consumption by determining the location and size of the capacitors. MATLAB and SIMULINK develop the optimization program and electrical distribution model. The three-phase electrical distribution system model have been used for testing the effectiveness of the optimization technique is deployed at the UiTM Science and Technology Tower (Block 4).
\end{abstract}

Keywords: energy efficiency; PSO; optimal; capacitor sizing; capacitor placement.

Author Correspondence, e-mail: fuadlatip@salam.uitm.edu.my

doi: http://dx.doi.org/10.4314/jfas.v9i4s.33

\section{INTRODUCTION}

Capacitors or usually shunt capacitors have been used in power system for many years. The common applications of capacitors are to reduce active power loss and improving the power factor of the system [1]. Nowadays, a lot of modification and improvement have been made to 
increase the capability and functionality of capacitors [2]. However, harmonics distortion level will amplify when shunt capacitors are installed randomly without proper calculation in distorted electrical distribution system no matter how good or reliable the capacitors are [3-6]. Thus, in order to determine the optimal place and size of the capacitors, artificial intelligence optimization technique are going to be used.

A lot of researchers are taking consideration of the presence of harmonic current and voltage to optimize the placement and size of the capacitors when using optimization technique such as Genetic Algorithms (GA) [7], Genetic Algorithms with Simulated Annealing (GA-SA) [8] and Particle Swarm Optimization (PSO) [5] in a balanced three-phase system. For unbalanced three phase system, Particle Swam Optimization (PSO) [9] and Harmony Search Approach (HSA) [10] have been implemented to determine the most suitable placement and size of the shunt capacitors for the distorted distribution system. From their study [5, 7-10], when the shunt capacitors are installed at a suitable place with proper location and size, the performance of the electrical distribution system will increase as the total power loss is reduced while still maintaining the system stability. Hence, by implementing artificial intelligence optimization technique, searching for the optimal capacitors sizing and location can be done with ease.

Most of the optimization for optimal capacitor sizing and location on electrical distribution system are based on historical data rather than present data [7-10]. This technique can bring difficulties in the future as the load will keep increasing, but the capacitor size and location are already fixed. When this happened, the system will become distorted and unstable thus lead to more power consumption and increase in harmonics [11]. The purpose of this project is to overcome this limitation by using real-time data for the optimization. By using real-time data, the size and location of the capacitors can be variable based on the present load using artificial intelligence optimization technique, in this case, Particle Swarm Optimization (PSO). Even though the load is increases or decreases, it will not become a problem as the algorithm used is based on real-time analysis, meaning that the size and location of the capacitors are changing hourly depending on the load.

The objective of this paper is to design and develop real-time analysis on determining the 
optimal capacitor sizing and placement for UiTM S\&T tower by using artificial intelligence (A.I.) Particle Swarm Optimization (PSO) [14] technique and also to reduce the UiTM S\&T Tower electricity bill.

\section{METHODOLOGY}

There are two parts of the process that are involved in developing this project. The first process is constructing the electrical distribution system model in SIMULINK [12] software. The distribution system model that are being used for this study is UiTM Science and Technology (S\&T) Tower (Block 4). For the second process, artificial intelligence technique, i.e. PSO is going to be used to find the optimal capacitor placement and sizing in the distribution system. The idea of this optimization is that the PSO will optimize the system based on real-time analysis.

By referring to Fig. 1, the data needed for the optimization process comes from the smart meter. The smart meter will record the total power consumed by the load and upload it to the online database. By integrating the online database with the MATLAB software, the optimization can be done in real time. When the optimization is finished, the optimal capacitor placement and size are going to be upload back into the database, so that the user can set the desired placement and size for the capacitor thus making the distribution system more efficient in term of energy used. For the purpose of this study, this paper will only cover the optimization part. The total power assumed in this study is based on the maximum load that the system can handle and also based on the load trending.

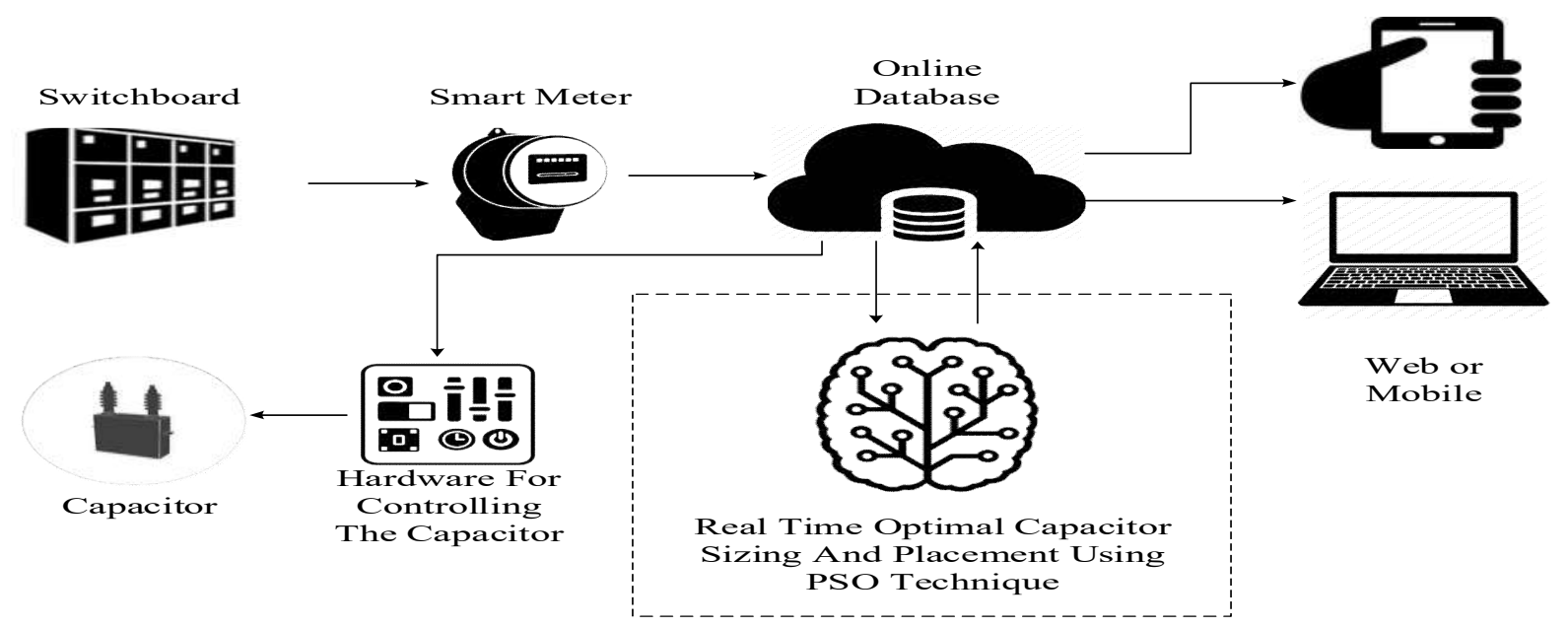

Fig.1. Overall system model 


\subsection{Development of Electrical Power Distribution System Using SIMULINK in} MATLAB

Three phase power system is called balanced when both three phase voltages and currents have the same amplitude and are phase shifted by $120^{\circ}$ with each other. If either of this condition is not met, the electrical system is called unbalanced. For the purpose of this study, a balanced three-phase electrical distribution system model has been developed. MATLAB and SIMULINK were chosen for the development of this system as this software have a very good reputation in performing analysis on the electrical distribution system. SIMULINK is an engineering software that executes its program in a graphical manner using circuitry diagram, block and multiple types of graph. Before constructing the distribution system into SIMULINK, the schematic diagram of the system must be analyzed first. To design the model in a very organized way, the distribution system was designed into some separate parts or subsystem as shown in the below section.

\subsubsection{Nodes or Buses (Riser)}

For Fig. 2, the left figure shows the subsystem while the internal component of the subsystem shows in the right figure. This subsystem is important for this study because measurement for incoming voltage and current in each bus comes from this subsystem. By using 'tag' to send signals to scopes without using physical wire, the model of this distribution system will look more organized.
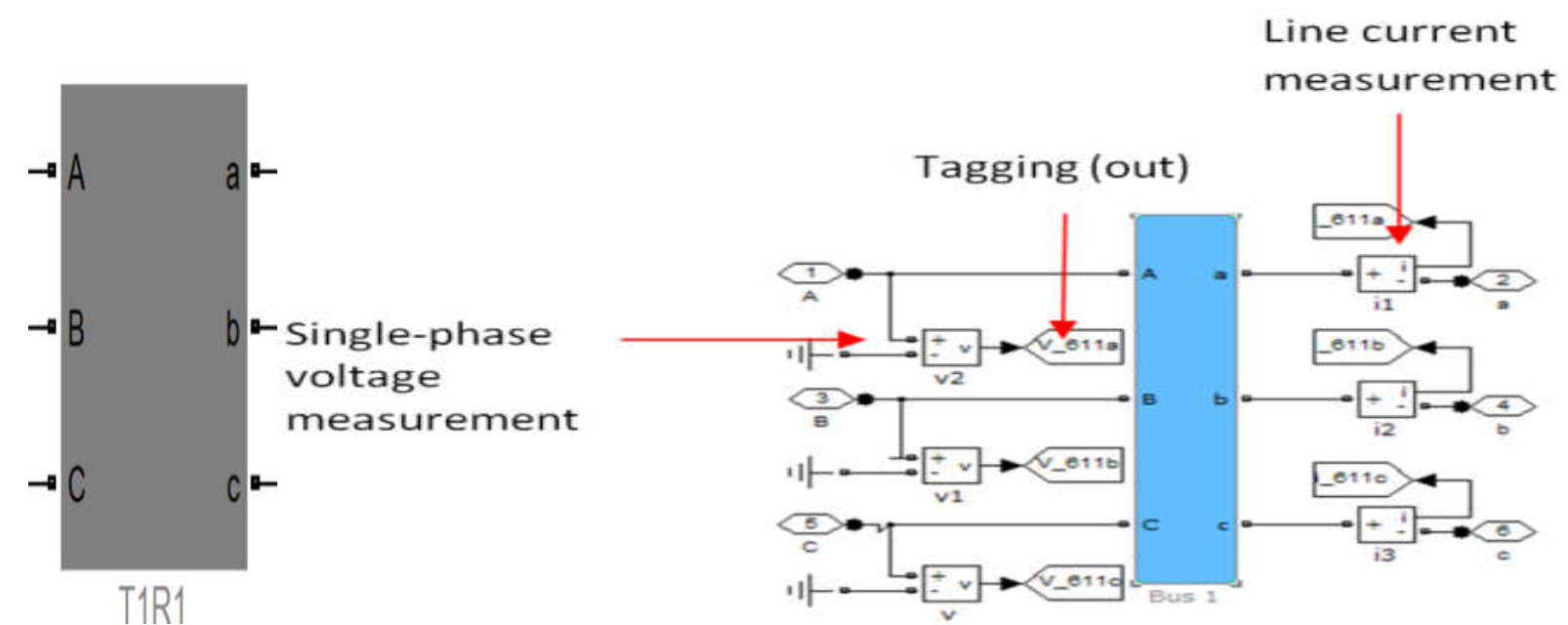

Fig.2. Bus subsystem (left) and its internal component (right)

\subsubsection{Distribution Lines}

For Fig. 3, the left figure shows the subsystem while the internal component of the subsystem shows in the right figure. This subsystem is designed for the purpose of calculating and identifying the power losses in lines (excessive power consumed by the cable). The length 
cable, positive and zero sequence value of the impedance cable is inserted into 'three-phase pi section' component.
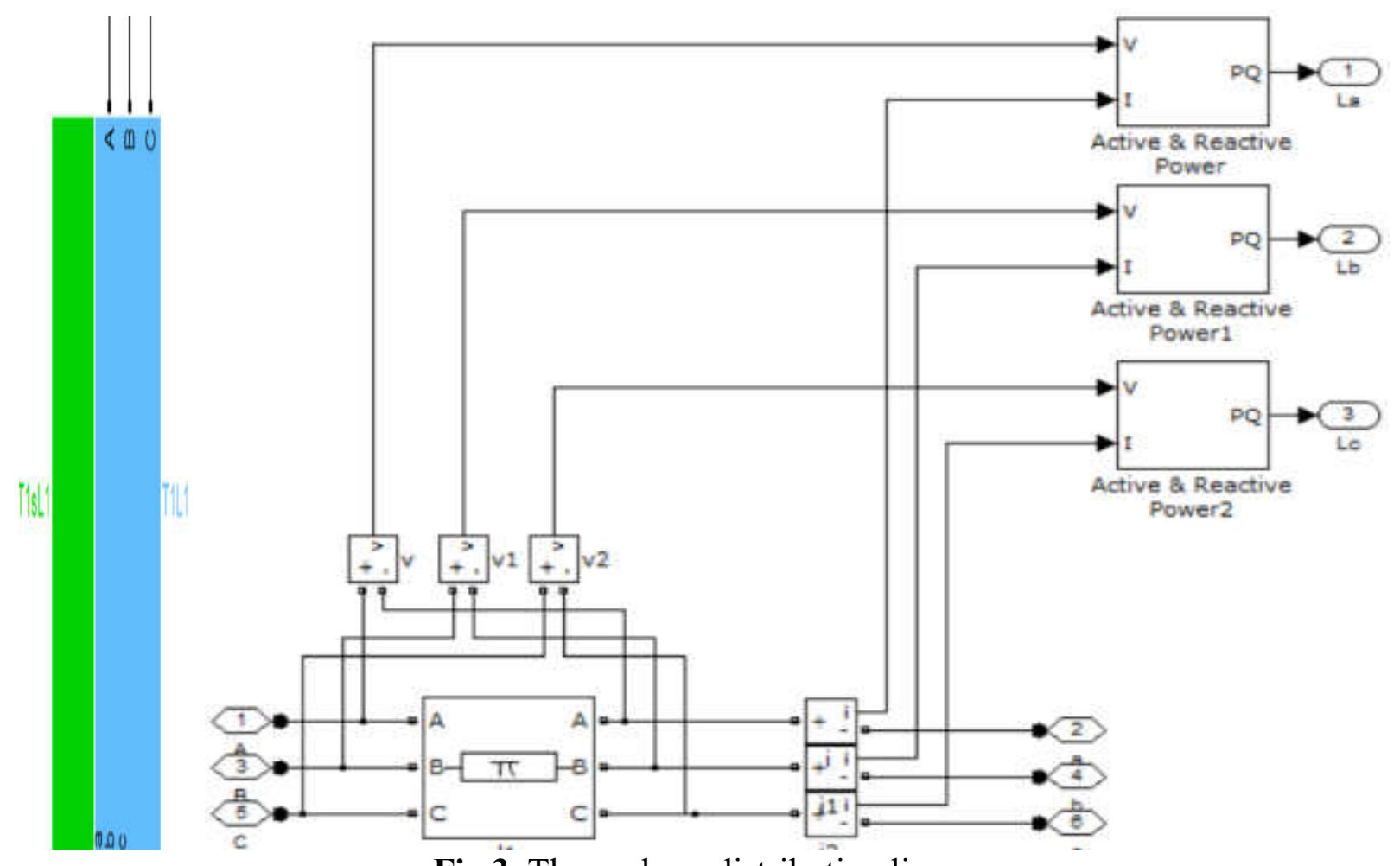

Fig.3. Three-phase distribution lines

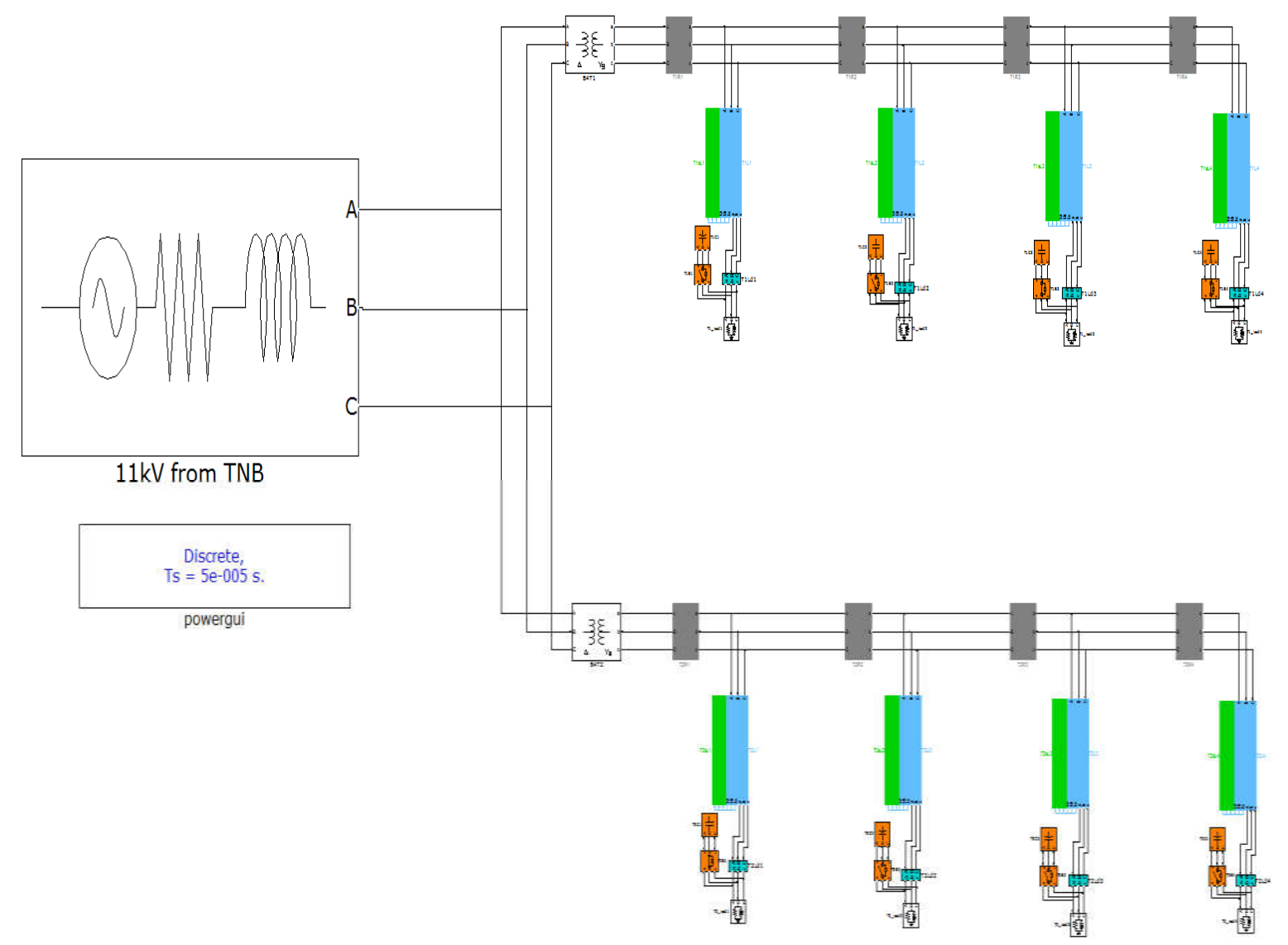

Fig.4. Electrical distribution system in SIMULINK 


\subsubsection{Individual Components/Equipment}

Besides designing the subsystem to simplify the connection, some component or electrical equipment models were directly applied in the distribution model which are:

- Transformers

- Scopes

- Voltage source/incoming

- Circuit breakers

- Three-phase load

- Capacitors

Fig. 4 shows the overall electrical distribution system for this study. After the distribution system model have been simulated, all the required measurement parameters that are needed for further optimization were extracted and calculated.

\subsection{Application of Particle Swarm Optimization (PSO) Technique for Optimal Capacitor Sizing and Placement}

PSO technique is used for this study to determine the suitable sizing and placement of the capacitor. PSO was chosen for this study because of its good reputation for solving optimization problems. MATLAB are going to be used for developing this algorithm because of MATLAB's ability to integrate the developed algorithms into the electrical distribution model in the SIMULINK. Fig. 5 shows how the PSO works for this study.

\subsubsection{Step 1-Parameters Declarations}

The first step before writing a program in MATLAB is to declare the related parameters. Table 1 shows the involved parameter to developed and apply PSO algorithm in this study. 


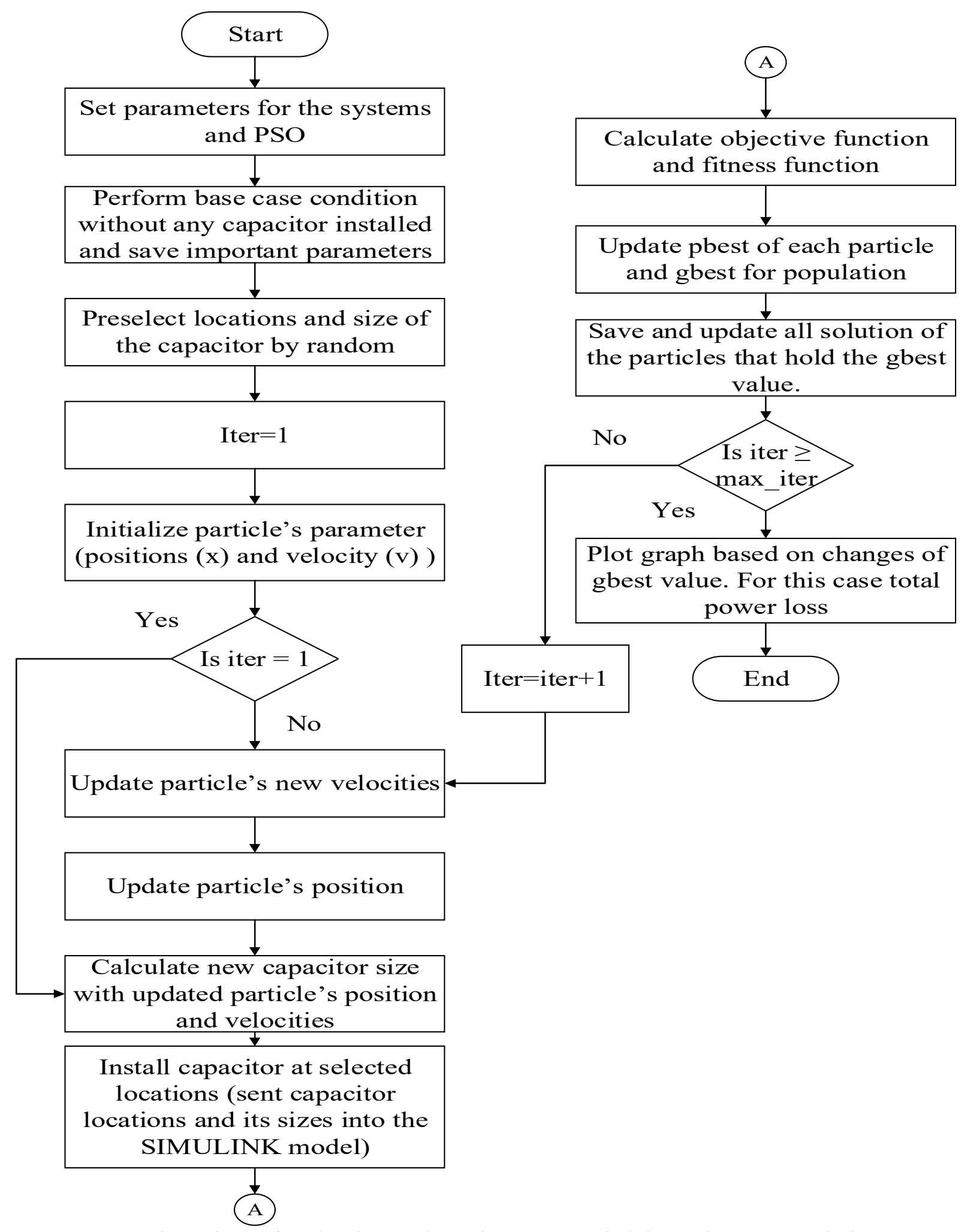

Fig.5. Flow chart of optimal capacitor placement and sizing using PSO technique

\subsubsection{Step 2-Simulate Base Case Conditions}

Base case simulation was executed at the early stage of optimization process to record the performance of the distribution system before the installation of capacitor and sizing process. Important parameters are going to be saved for further study. 
Table 1. Particle swarm parameters

\begin{tabular}{cc}
\hline Parameter & Value \\
\hline Number of Particles & 5 \\
Maximum Iterations & 10 \\
learning rate for individual ability & 2.05 \\
Social influence & 2.05 \\
Minimum weight & 0.4 \\
Maximum Weight & 0.9 \\
Velocity Control Factor & 1 \\
Minimum particle's position & 0 \\
Maximum particle's position & 1 \\
Minimum Velocity & -1 \\
Maximum Velocity & 1 \\
\hline
\end{tabular}

\subsubsection{Step 3-Preselect the Location and Size of the Capacitor}

As discussed in the early section of this paper, optimal capacitor placement and sizing problems are to find the optimal locations and sizing of the capacitor to be placed in a distribution system. In this study, random location and sizing are the techniques that will be used. The approaches will generate a matrix consist of value either ' 1 ' or ' 0 ' to indicate the on and off of the capacitor. If the capacitor is on, a random value of capacitor from $10 \mathrm{kV}$ ar until $300 \mathrm{kVar}$ is going to be selected.

\subsubsection{Step 4-Each Particle Holds Multidimensional Values of Their Position and}

\section{Velocity}

The initial state of the particles is in a static condition, where each particle starts at different positions. Based on that topology, the initial position of each particle was randomly generated. In order to control the search space area of each particle, the initial position is bound to the minimum value of ' 0 ' and the maximum value of ' 1 '. At initial or starting of the searching process, each particle has no memory of their best position. Thus, their starting position was taken as their best position. Because of the static starting condition of the particles, the initial velocity of each particle is set as zero.

\subsubsection{Step 5: Optimization Process}

During the optimization process, each of the particles in a swarm population will keep moving to their new positions in order to search for the best solution. Their velocity toward 
next position is based on their memory of their own best position and the memory of particles that hold the global best position. The method used for the particles to update their velocity for this study is by using constriction factor in Equation (1)

$\mathrm{V}_{\mathrm{i}}(\mathrm{k})=\mathrm{x}\left[\mathrm{V}_{\mathrm{i}}(\mathrm{k}-1)+\mathrm{c}_{1} \mathrm{r}_{1}\left(\right.\right.$ pbest $\left.\left._{\mathrm{i}}(\mathrm{k})-\mathrm{x}_{\mathrm{i}}(\mathrm{k}-1)\right)+\mathrm{c}_{2} \mathrm{r}_{2}\left(\operatorname{gbest}(\mathrm{k})-\mathrm{x}_{\mathrm{i}}(\mathrm{k}-1)\right)\right]$

$\mathrm{x}=\frac{2 \mathrm{k}}{\mid 2-\emptyset-(\varnothing(\varnothing-4) \mid}$

where $\mathrm{K} \in[0,1], \varnothing=\mathrm{c}_{1} \mathrm{r}_{1}+\mathrm{c}_{2} \mathrm{r}_{2}$ and $\varnothing \geq 4$.

For velocity control, to ensure the particles search area is within the space area, the velocity of each particle is controlled by setting some condition based on Equation Erreur ! Source du renvoi introuvable.).

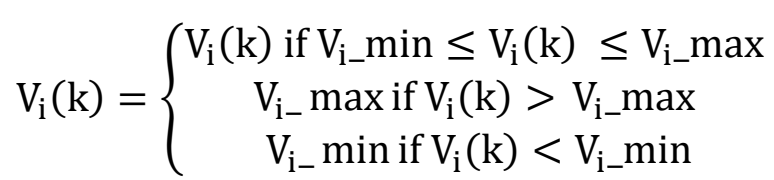

where $\mathrm{V}_{\mathrm{i}_{-}} \max =\delta\left(\mathrm{x}_{\mathrm{i}_{\max }}-\mathrm{x}_{\mathrm{i}_{\min }}\right), \mathrm{V}_{\mathrm{i}_{-}} \min =\delta\left(\mathrm{x}_{\mathrm{i}_{\min }}-\mathrm{x}_{\mathrm{i}_{\max }}\right)$ and $\delta \in[0,1]$.

For this study, the velocity constant factor $\delta$ is considered as 1 because lower value of velocity constant factor can cause restriction to the maximum and minimum value of particles. In PSO technique, particles updated their position by adding their new velocity with the previous position. The figure on how the particles works are shown in Fig. 6.

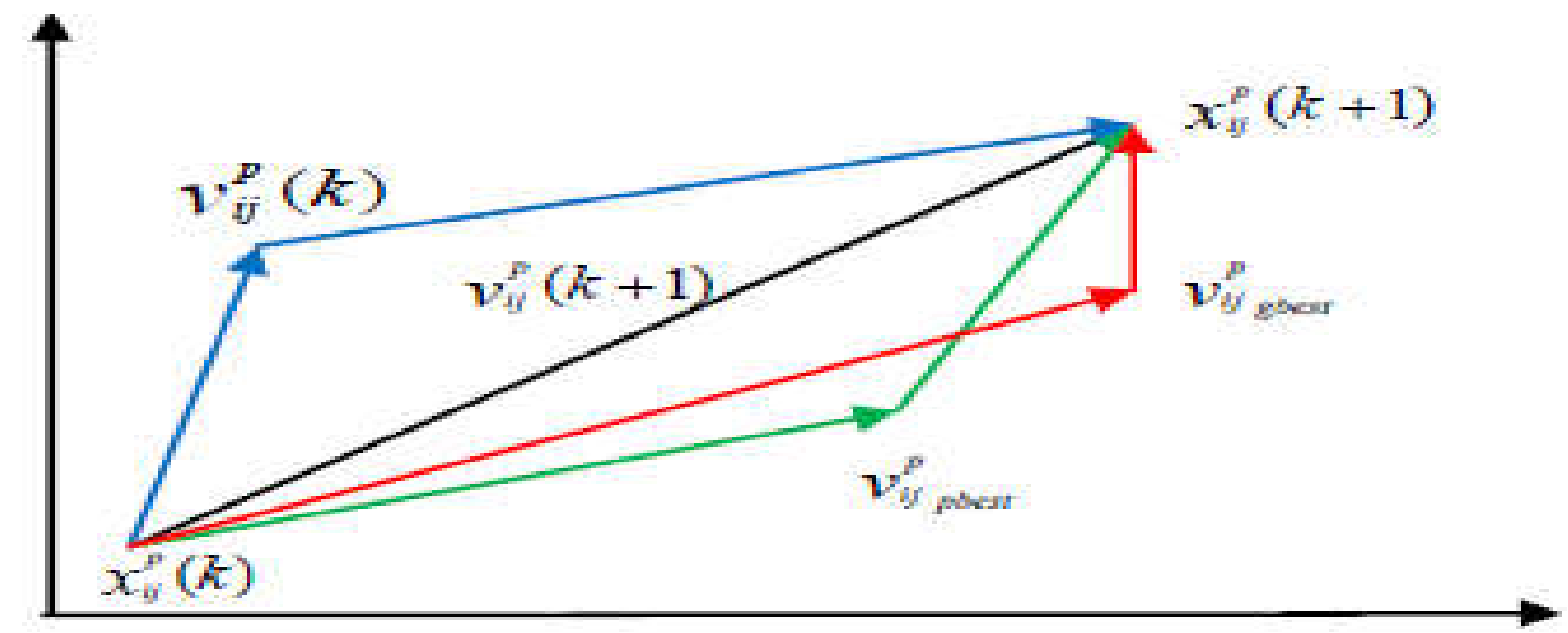

Fig.6. Principle of PSO technique

For position control, there is a possibility of the particles to fly outside of the search space region which means the value of particles is below ' 0 ' or exceed ' 1 '. To overcome this, some condition was made to control the particles whether to update their position or not in Equation Erreur ! Source du renvoi introuvable.). 
$x_{i}(k)=\left\{\begin{array}{c}x_{\text {max }}, V_{i}(k)=0 \text { if } x_{i}(k)>x_{\max } \\ x_{\text {min }}, V_{i}(k)=0 \text { if } x_{i}(k)>x_{\min } \\ x_{i}(k) \text { if } x_{\min } \leq x_{i}(k) \leq x_{\max }\end{array}\right.$

To relate the topology of the particles movement and the capacitor size, Equation Erreur !

Source du renvoi introuvable.) was used in order to generate the capacitor size in kVar.

$\mathrm{Q}_{\mathrm{i}}(\mathrm{k})=\left(\mathrm{Q}_{\mathrm{i}_{\text {max }}}-\mathrm{Q}_{\mathrm{i}_{\text {min }}}\right) \mathrm{x}_{\mathrm{i}}(\mathrm{k})+\mathrm{Q}_{\mathrm{i}_{\text {min }}}$

After completing the procedure for calculating the capacitor size, a matrix with a dimension of transformers and bus number will be generated as shown in Equation Erreur ! Source du renvoi introuvable.).

$\mathrm{Q}_{\mathrm{i}}(\mathrm{k})=\left(\begin{array}{cccc}\mathrm{Q}_{1 \mathrm{a}} & \mathrm{Q}_{1 \mathrm{~b}} & \mathrm{Q}_{1 \mathrm{c}} & \mathrm{Q}_{1 \mathrm{~d}} \\ \mathrm{Q}_{2 \mathrm{a}} & \mathrm{Q}_{2 \mathrm{~b}} & \mathrm{Q}_{2 \mathrm{c}} & \mathrm{Q}_{2 \mathrm{~d}}\end{array}\right)$

The following matrix will be sent to the SIMULINK program to simulate the distribution system with a capacitor installed. After the simulation is done, all required data will be recorded. For optimization process which involves population, fitness evaluation is the process to choose the best candidate that hold the best solution. The 'best' solution is not necessarily referred to the objective function alone. In this study, the fitness equation was developed by modifying the objective function. Below is the equation for the objective function of Equation Erreur! Source du renvoi introuvable.) and fitness function in Equation Erreur ! Source du renvoi introuvable.) respectively.

$\min . \mathrm{f}(\mathrm{x})=$ total_power_loss

fit $(\mathrm{x})=\frac{1}{\text { total_power_loss }}$

The constraint is classified into two groups which are uncontrolled and control constraint. For this study, one of the constraints involved is the uncontrolled constraint which is power factor. Even though the power factor is controlled base on capacitor size, it is still considered and observed in this process to filter which particles hold a solution that passes the constraints. The fitness evaluation in term of power factor constraint is shown in Equation Erreur ! Source du renvoi introuvable.).

fit $(\mathrm{k})=\left\{\begin{array}{c}\text { fit }(\mathrm{k}) \text { if } 0.65 \geq \text { power_factor } \leq 0.9 \\ 0 \text { other wise }\end{array}\right.$

In order to update their pbest, each particle will compare their current fitness value with their own personal best of fitness value (pbest). Updating the gbest value of a particle population 
also use the concept of comparison, however, it differs from updating pbest since there is only one gbest among all particles. Thus, each particle will compare their current fitness value with the single value of gbest.

After all of the pbest and gbest value have been recorded, the optimization process will keep on repeating until the end of desired iterations.

\subsection{Case Study}

This project has been implemented in UiTM Science and Technology (S\&T) Tower (Block 4). This building electrical distribution system consists of 2 transformers and 8 risers.

Before the optimization process, the electrical distribution system of UiTM Science and Technology (S\&T) Tower (Block 4) has been constructed using SIMULINK. The load flow of the system has been simulated to get the desired parameters for further optimization. For optimization process, Particle Swarm Optimization (PSO) [15] has been introduced and implemented in the distribution system model. There are several cases that have been considered for this study. For the first case, the total power loss will be determined in two states which are before installation of the capacitor and after installation. The reason for simulating this two different condition is to ensure that the system is optimized and improved when the capacitor is present on the system. For the next case, the simulation will be done in three different conditions. These conditions are when the load is in $45 \%, 80 \%$ and $35 \%$ of the total full load power. This case is introduced to identify the different of sizing and placement of capacitors when the load is varied.

For each of the stated cases, the optimization problem has been solved and optimal capacitor placement and sizing have been determined and recorded.

\section{RESULTS AND DISCUSSION}

The results obtained in this study are obtained by using MATLAB and SIMULINK software which are used to develop PSO and executing the simulation respectively. The optimization process was executed by using Toshiba laptop with the specification of Intel i5 processor, 4GB of RAM and $2.5 \mathrm{GHz}$ speed. The developed algorithms were tested on UiTM Science and Technology (S\&T) Tower (Block 4). The number of capacitors to be installed is not to 
exceed the total riser in the distribution system, in this case, 8 risers.

\subsection{Case 1: Simulation in Full Load Condition}

For the first case, the simulation is done in full load condition. Table 2 and Table 3 show the total power consumed by the load in each transformer and riser.

Table 2. Load data for transformer 1

\begin{tabular}{ccccc}
\hline Bus (Riser) & $\mathbf{1}$ & $\mathbf{2}$ & $\mathbf{3}$ & $\mathbf{4}$ \\
\hline Real Power, P (kW) & 320 & 530 & 380 & 360 \\
Reactive Power, Q (kVar) & 326 & 541 & 388 & 367 \\
\hline
\end{tabular}

Table 3. Load data for transformer 2

\begin{tabular}{ccccc}
\hline Bus (Riser) & $\mathbf{1}$ & $\mathbf{2}$ & $\mathbf{3}$ & $\mathbf{4}$ \\
\hline Real Power, P (kW) & 350 & 380 & 380 & 0 \\
Reactive Power, Q (kVar) & 357 & 387 & 388 & 0 \\
\hline
\end{tabular}

For base case (without capacitor) and after optimization process (with capacitor) simulation, the result obtained is shown in Erreur! Source du renvoi introuvable.4-6 respectively. Based on the results obtained, the total power loss is reduced after the most optimal capacitor placement and sizing has been installed in the system model. Besides total power loss, the power factor is also improved dramatically after the system was successfully optimized. The developed PSO was able to determine the most optimal locations and size of the capacitor such that the overall system is optimized. The convergence characteristics of the PSO for this optimal placement and sizing of the capacitor problem with the total power loss being the objective are illustrated in Fig. 7.

Table 4. Results of base-case condition (without capacitor)

\begin{tabular}{cc}
\hline Parameters & Value \\
\hline Total power loss (P) & $145.254 \mathrm{~kW}$ \\
Total power loss (Q) & $89.442 \mathrm{kVar}$ \\
Power factor (TX.1, TX.2) & $0.712,0.715$ \\
\hline
\end{tabular}

Table 5. Optimal capacitor placement and sizing

Capacitor Placement and Sizing

$\begin{array}{lllll}\text { Riser } & 1 & 2 & 3 & 4\end{array}$




\begin{tabular}{ccccc}
\hline TX.1(kVar) & 250 & 270 & 280 & 220 \\
TX.2(kVar) & 270 & 250 & 210 & 0
\end{tabular}

Table 6. Results after optimization process (with capacitor)

\begin{tabular}{cc}
\hline Parameters & Value \\
\hline Total power loss (P) & $107.066 \mathrm{~kW}$ \\
Total power loss (Q) & $66.513 \mathrm{kVar}$ \\
Power factor (TX.1, TX.2) & $0.855,0.863$
\end{tabular}

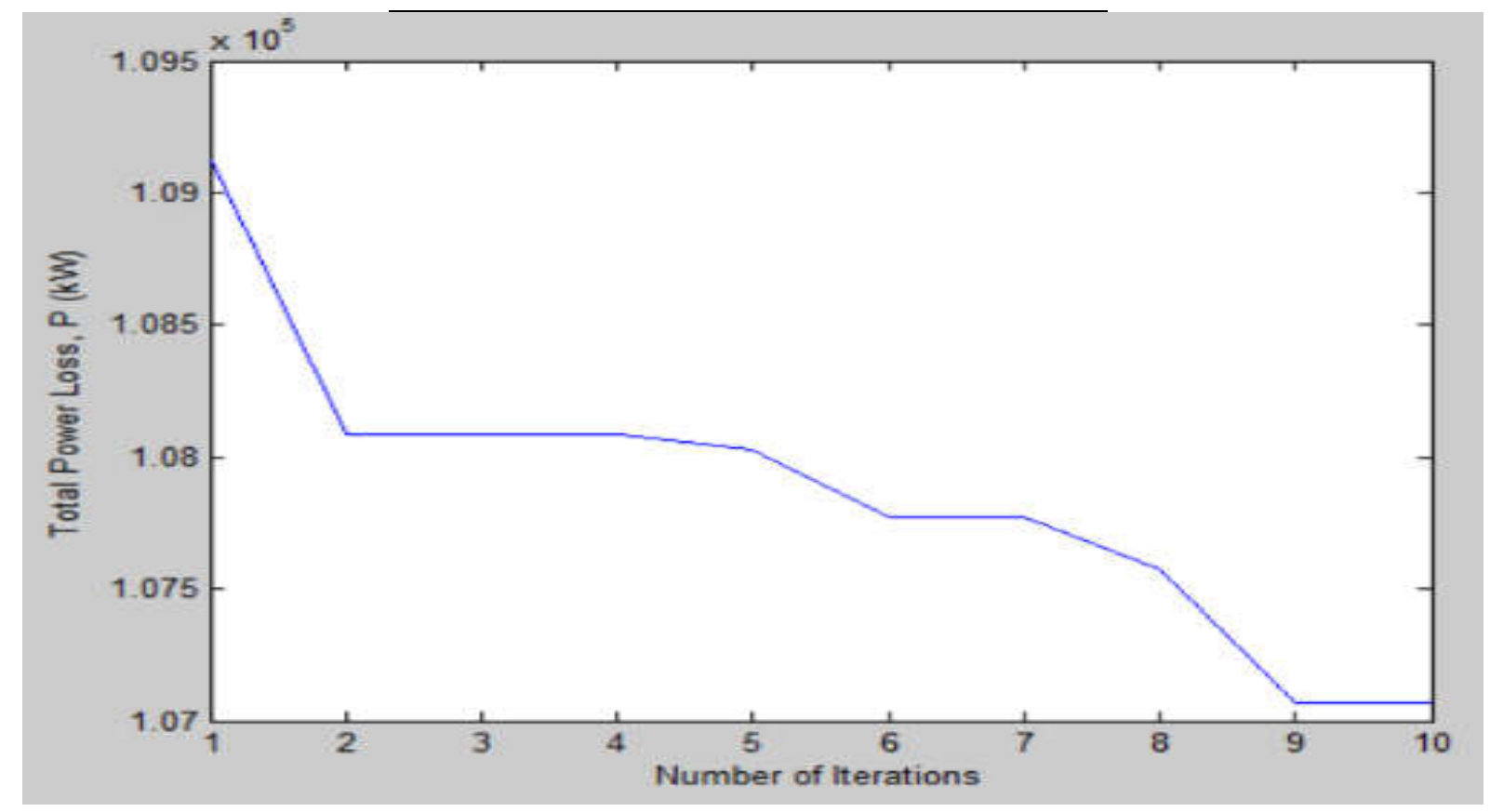

Fig.7. Graph of convergence characteristic

\subsection{Case 2: Simulation in $45 \%, 80 \%$ and $35 \%$ of the Total Full Load Power}

For the second case, the simulation is done in $45 \%, 80 \%$ and $35 \%$ of the total full load power. The purpose of this study is to differentiate the capacitor values and locations when the total power consumed by the load is varied. The number 45\% (3.00 A.M-10.00 A.M), 80\% (10.00 A.M-3.00 P.M) and 35\% (3.00 P.M-9.00 P.M) of the total full load power comes from the load trending of a standard distribution system inside a building shown in Fig. 8 (assume that the trending is constant for every weekday). 


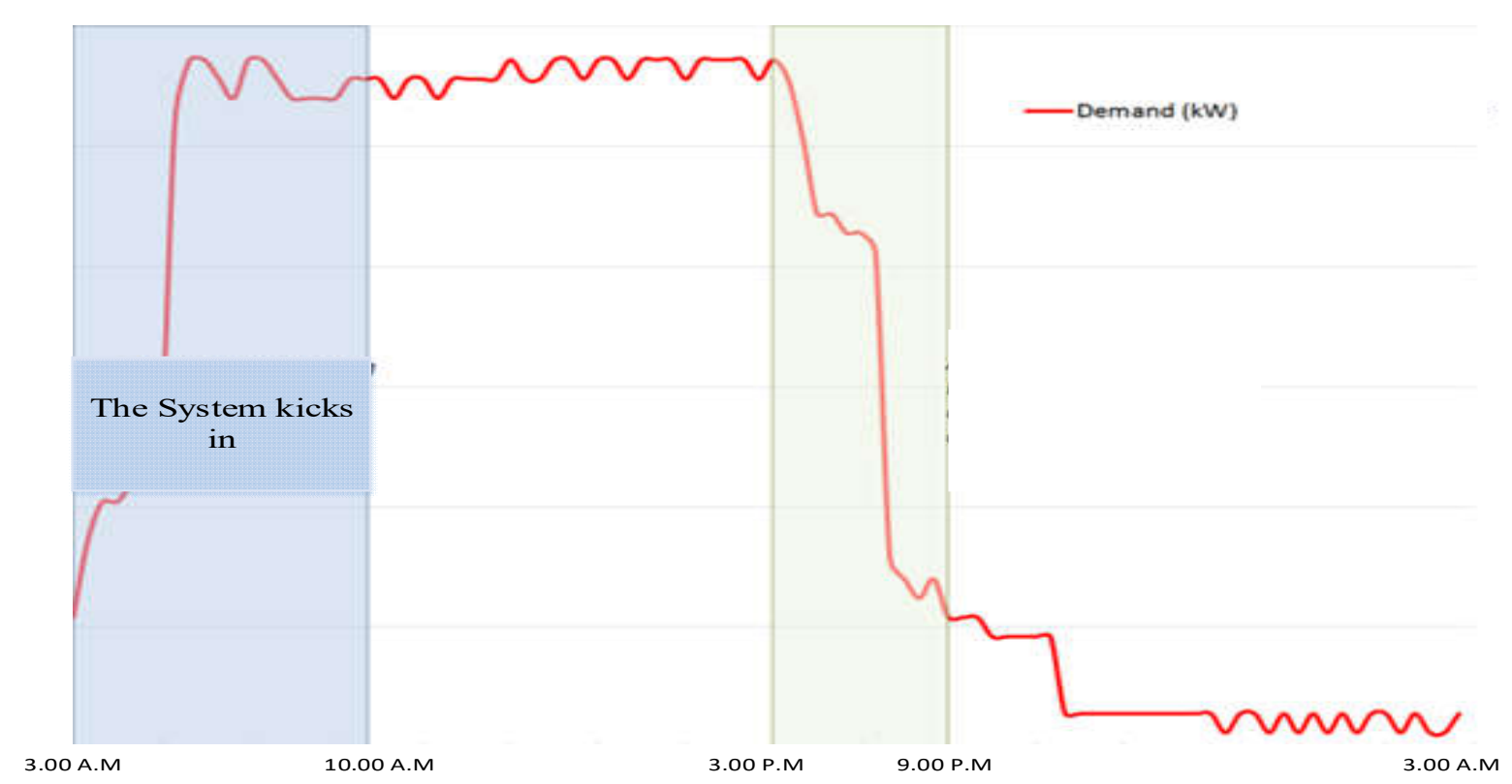

Fig.8. Daily load trending in a building

Table 7 shows the total power consumed by the load for each bus and transformer in the system.

Table 7. Load data for $35 \%, 45 \%$ and $80 \%$ of total load

\begin{tabular}{|c|c|c|c|c|c|c|}
\hline & & Bus (Riser) & 1 & 2 & 3 & 4 \\
\hline \multirow{4}{*}{ 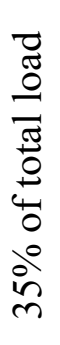 } & \multirow{2}{*}{ 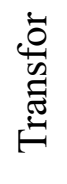 } & Real Power, P (kW) & 112 & 185.5 & 133 & 126 \\
\hline & & Reactive Power, Q (kVar) & 114.26 & 189.25 & 135.69 & 128.55 \\
\hline & \multirow{2}{*}{ 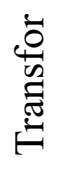 } & Real Power, P (kW) & 122.5 & 133 & 133 & 0 \\
\hline & & Reactive Power, Q (kVar) & 124.97 & 135.69 & 135.69 & 0 \\
\hline \multirow{4}{*}{ 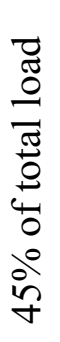 } & \multirow{2}{*}{ 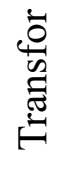 } & Real Power, P (kW) & 144 & 238.5 & 171 & 162 \\
\hline & & Reactive Power, Q (kVar) & 146.9 & 243.32 & 174.45 & 165.27 \\
\hline & \multirow{2}{*}{ 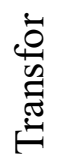 } & Real Power, P (kW) & 157.5 & 171 & 171 & 0 \\
\hline & & Reactive Power, Q (kVar) & 160.68 & 174.45 & 174.45 & 0 \\
\hline \multirow{4}{*}{ 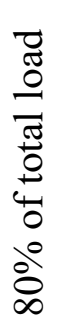 } & \multirow{2}{*}{ 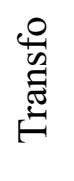 } & Real Power, P (kW) & 256 & 424 & 304 & 288 \\
\hline & & Reactive Power, Q (kVar) & 261.17 & 432.57 & 310.14 & 293.82 \\
\hline & \multirow{2}{*}{ 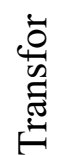 } & Real Power, P (kW) & 280 & 304 & 304 & 0 \\
\hline & & Reactive Power, Q (kVar) & 285.66 & 310.14 & 310.14 & 0 \\
\hline
\end{tabular}


Table 8. Results of base-case condition (without capacitor) for $45 \%, 80 \%$ and $35 \%$ of total load

\begin{tabular}{cccc}
\hline Percentage of Total Full Load Power & $\mathbf{3 5 \%}$ & $\mathbf{4 5 \%}$ & $\mathbf{8 0 \%}$ \\
\hline Total power loss, P (kW) & 21.179 & 34.142 & 98.179 \\
Total power loss, Q (kVar) & 13.315 & 21.318 & 60.632 \\
Power factor (TX.1, TX.2) & $0.72,0.727$ & $0.72,0.72$ & $0.71,0.716$ \\
\hline
\end{tabular}

Table 9. Optimal capacitor sizing and placement for 35\%, 45\% and $80 \%$ of total load

\begin{tabular}{ccccccc}
\hline \multicolumn{5}{c}{ Capacitor Placement and Sizing } \\
\hline 35\% of total load & Riser & 1 & 2 & 3 & 4 \\
& TX.1(kVar) & 120 & 110 & 40 & 70 \\
& TX.2(kVar) & 20 & 100 & 50 & 0 \\
$45 \%$ of total load & Riser & 1 & 2 & 3 & 4 \\
& TX.1(kVar) & 130 & 120 & 110 & 100 \\
& TX.2(kVar) & 130 & 130 & 30 & 0 \\
& Riser & 1 & 2 & 3 & 4 \\
& TX.1(kVar) & 300 & 300 & 190 & 70 \\
& TX.2(kVar) & 300 & 100 & 150 & 0
\end{tabular}

Table 10. Results after optimization process (with capacitor) for $35 \%, 45 \%$ and $80 \%$ of total load

\begin{tabular}{cccc}
\hline Percentage of Total Full Load Power & $\mathbf{3 5 \%}$ & $\mathbf{4 5 \%}$ & $\mathbf{8 0 \%}$ \\
\hline Total power loss, P (kW) & 15.924 & 24.804 & 72.949 \\
Total power loss, Q (kVar) & 10.098 & 15.68 & 45.213 \\
Power factor (TX.1, TX.2) & $0.861,0.829$ & $0.864,0.857$ & $0.865,0.857$
\end{tabular}




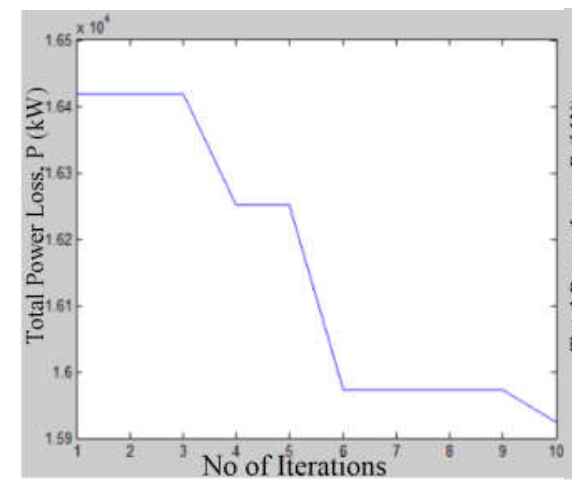

(a)

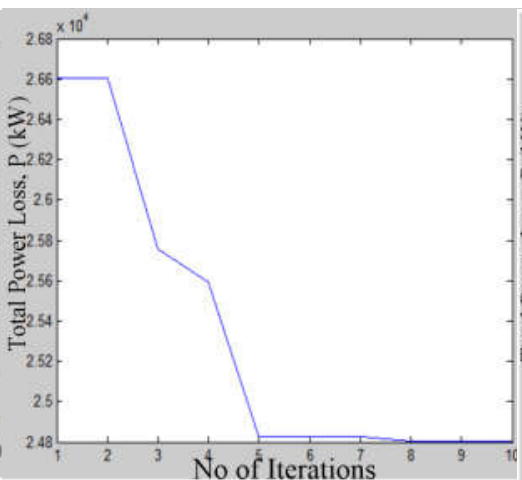

(b)

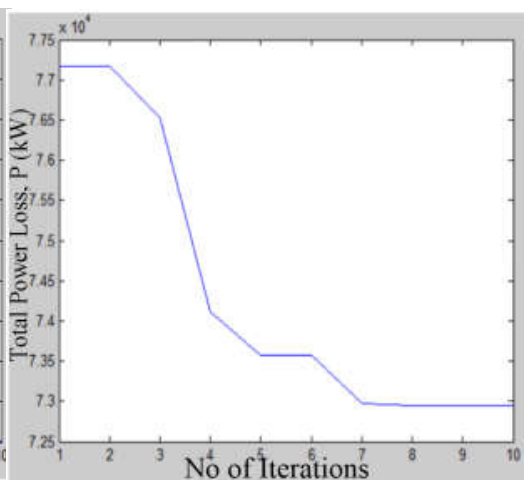

(c)

Fig.9. Graph of convergence characteristics for (a) 35\% of total load power (b) $45 \%$ of total load power (c) $80 \%$ of total load power

For base case (without capacitor) and after optimization process (with capacitor) simulation, the result obtained is shown in Table 8-10 respectively. Based on the result obtained, the total power loss is reduced after the most optimal capacitor placement and sizing has been installed in the system model. Besides total power loss, the power factor is also improved dramatically after the system was successfully optimized. Based on the result above, the optimal size and placement of the capacitor are not the same for every load demand. This proves that with higher or lower load demand, the optimal capacitor location and sizing will be different. By implementing the real time analysis, the system will always be updated with the most optimal capacitor placement and sizing during that time. The convergence characteristics of the PSO for this optimal placement and sizing of the capacitor problem with the total power loss being the objective are illustrated in Fig. 9 (a)-(c).

\section{CONCLUSION}

Excessive energy consumption is a very hot topic nowadays as this problem bring major impact on the electricity bill and also to the environment, which can cause global warming. This problem comes from power quality problems in the electrical distribution system. Power quality problem can exist in both consumer and distributor part, but this paper focuses only on the consumer part. Because of this phenomena, energy efficiency is introduced and widely used in most countries nowadays. In this paper, the developed PSO-based algorithm was tested on UiTM Science and Technology (S\&T) Tower (Block 4) distribution system to find the optimal locations and sizes of capacitors. The objective of this paper was to minimize the total real power loss by determining the optimal capacitor placement and sizing. The simulation results show that by having controllable capacitors in the distribution system, it can minimize the losses more effectively thus making the system more energy [16] efficient. 
This is crucial for distribution system automation management. Because of some limitation, harmonics injection is not included in this paper. For future recommendation, proper calculation and observation of total harmonic distortion (THD) must be considered when installing the capacitors into the system [13] to avoid excessive harmonics.

\section{ACKNOWLEDGEMENTS}

We would like to extend our acknowledgment to Universiti Teknologi MARA (UiTM) and to those who have directly and indirectly contributed to our project. This research is funded by the Fundamental Research Grants Scheme Research, Ministry of Higher Education Malaysia (FRGS/1/2014/TK03/UiTM/02/14).

\section{REFERENCES}

[1] Benitez J. Application of capacitors for power factor correction of industrial electrical distribution systems. In Record of Conference Papers., Industry Applications Society 39th IEEE Annual Petroleum and Chemical Industry Conference, 1992, pp. 77-86

[2] Zhang M, Sun H. Improvement of an SVC using an active power filter connected in parallel with synchronous switched capacitors. In 2nd IEEE Conference on Industrial Electronics and Applications, 2007, pp. 212-216

[3] Rani D S, Subrahmanyam N, Sydulu M. Self adaptive harmony search algorithm for optimal capacitor placement on radial distribution systems. In IEEE International Conference on Energy Efficient Technologies for Sustainability, 2013, pp. 1330-1335

[4] Sattianadan D, Sudhkaran M, Vijayakumar K, Vidyasagar S. Optimal placement of capacitor in radial distribution system using PSO. In International Conference on Sustainable Energy and Intelligent Systems, 2011, pp. 326-331

[5] Sonwane P M, Kushare B E. Optimal capacitor placement and sizing for enhancement of distribution system reliability and power quality using PSO. In IEEE International Conference for Convergence of Technology, 2014, pp. 1-7

[6] Eajal A A, El-Hawary M E. Optimal capacitor placement and sizing in unbalanced distribution systems with harmonics consideration using particle swarm optimization. IEEE Transactions on Power Delivery, 2010, 25(3):1734-1741

[7] Masoum M A, Ladjevardi M, Jafarian A, Fuchs E F. Optimal placement, replacement and sizing of capacitor banks in distorted distribution networks by genetic algorithms. IEEE Transactions on Power Delivery, 2004, 19(4):1794-801 
[8] Ghoshal S K, Maiti A K, Kastha G S. Luminescence properties of ultra-pure pyridine. Journal of Luminescence, 1984, 31:541-545

[9] Razak M A, Othman M M, Shahidan M B, Ariffin J, Musirin I, Kamal M F, Zakaria Z, Yahya A, Kari M N, Osman M F. Optimal capacitor placement and sizing in an unbalanced three-phase distribution system using particle swarm optimization technique. In IEEE 8th International Power Engineering and Optimization Conference, 2014, pp. 624-629

[10] Muthukumar K, Jayalalitha S. Harmony search approach for optimal capacitor placement and sizing in unbalanced distribution systems with harmonics consideration. In IEEE International Conference on Advances in Engineering, Science and Management, 2012, pp. 393-398

[11] Fitriana Suhartati D F, Penangsang O, Soeprijanto A. Capacitor placement and sizing in distorted distribution systems using simplified direct search algorithm. Journal of Clean Energy Technologies, 2014, 2(4):317-321

[12] Zamboni L. Getting started with Simulink. Birmingham: Packt Publishing Ltd., 2013

[13] Latip M F, Udin M K, Othman M M, Yassin I M, Rizman Z I, Zaini N, Hidayat M N, Aminuddin N, Herman S H, Saad H, Rahiman M H. Implementation of fuzzy logic-based final year project student-supervisor matching system. International Journal of Advanced and Applied Sciences, 2017, 4(4):159-163

[14] Masrom S, Abidin S Z, Omar N, Rahman A S, Rizman Z I. Dynamic parameterizations of particle swarm optimization and genetic algorithm for facility layout problem. ARPN Journal of Engineering and Applied Sciences, 2017, 12(10):3195-3201

[15] Yassin I M, Zabidi A, Ali M S, Tahir N M, Abidin H Z, Rizman Z I. Binary particle swarm optimization structure selection of nonlinear autoregressive moving average with exogenous inputs (NARMAX) model of a flexible robot arm. International Journal on Advanced Science, Engineering and Information Technology, 2016, 6(5):630-637

[16] Kassim A H, Miskon M T, Rustam I, Zain M M, Arifin A M, Rizman Z I. Optimum storage size for thermal energy storage system. ARPN Journal of Engineering and Applied Sciences, 2017, 12(10):3304-3307

\section{How to cite this article:}

Rahman AHA, Latip MFA, Zaini N. Optimal capacitor sizing and placement based on real time analysis using pso for energy efficiency improvement

. J. Fundam. Appl. Sci., 2017, 9(4S), 580-597. 